\title{
Carboplatin and weekly paclitaxel chemotherapy in hemodialysis patient with advanced lung cancer and severe comorbidity: effect of the drugs and their chemical intermediates
}

\author{
Shigeru Tanaka
}

Received: 8 July 2014/Accepted: 28 July 2014/Published online: 15 August 2014

(C) The Author(s) 2014. This article is published with open access at Springerlink.com

\begin{abstract}
In advanced non-small-cell lung cancer (NSCLC) patients with severe comorbidity or who are elderly, significant differences exist at the induction of chemotherapy. A 68-year-old man with a history of severe aortic stenosis and cerebral infarction had been receiving hemodialysis for end-stage renal disease. On admission due to loss of consciousness caused by aortic stenosis, a mass in the upper lobe of the right lung with a small amount of pleural effusion was detected. The patient was diagnosed with adenocarcinoma of lung (cT2bN1M1a, stage IV). A weekly regimen of paclitaxel in combination with carboplatin is less toxic than the standard regimen of administering both simultaneously. Therefore, this regimen is preferable for patients with severe comorbidity or who are elderly. For the present case, combination chemotherapy of carboplatin and weekly paclitaxel was selected and administered for four cycles. Tumor response was evaluated as stable disease and adverse events were tolerable. This combination was found to be a candidate regimen for advanced NSCLC patients receiving hemodialysis with severe comorbidity.
\end{abstract}

Keywords Non-small-cell lung cancer $\cdot$ Hemodialysis $\cdot$ Carboplatin · Weekly paclitaxel · Comorbidity · Drawbacks of the intermediates

\section{Introduction}

Advances in hemodialysis techniques have significantly prolonged survival for patients with end-stage renal disease (ESRD). The risk of cancer in patients with ESRD is higher than that in the general population. The combination of platinum and

\section{S. Tanaka $(\bowtie)$}

Department of General Medicine, Okazaki City Hospital, 3-1 Goshoai, Koryuji-cho, Okazaki,

Aichi 444-8553, Japan

e-mail: geruta@med.nagoya-u.ac.jp 
a

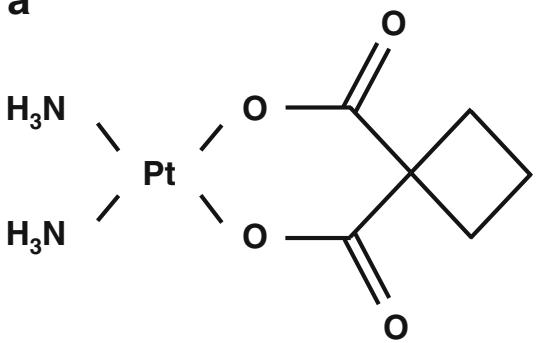

b<smiles>N[PH3](N)(N)Cl</smiles>

Fig. 1 Chemical structures of the anti-tumor drugs carboplatin (a) and cisplatin (b)

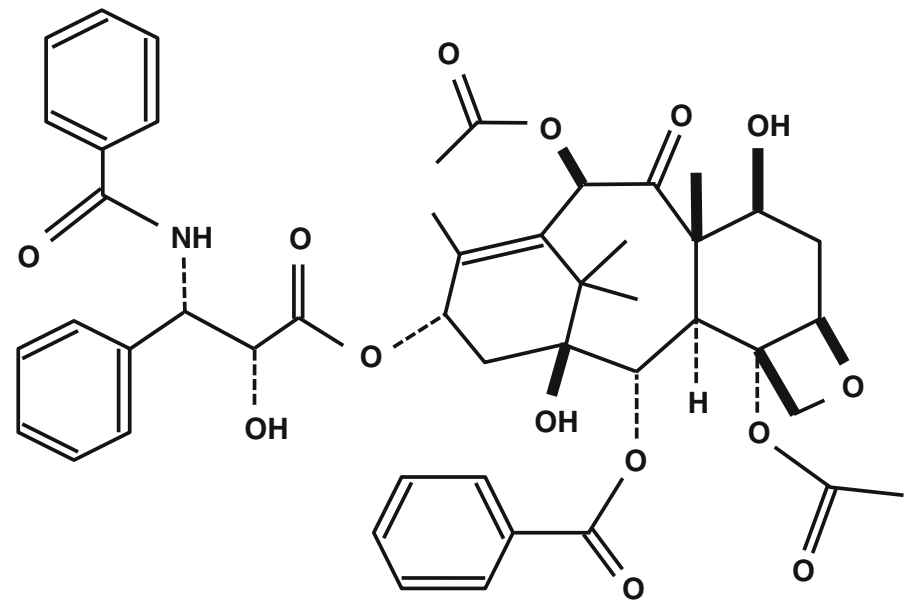

Fig. 2 Chemical structure of paclitaxel

other agents have been recommended as standard chemotherapy for advanced nonsmall-cell lung cancer (NSCLC), and paclitaxel is one of the agents in this combination [1-3]. Carboplatin (Fig. 1a) remains intact for longer times than cisplatin (Fig. 1b), therefore a greater proportion of the dose can be excreted in the urine and eliminated by hemodialysis in the case of the patients with ESRD [4]. Paclitaxel (Fig. 2) is mainly metabolized by hepatic cytochrome P450 enzymes and excreted into bile, therefore, a standard dose can be administered for patients with ESRD [5, 6]. Here, we report on the combination chemotherapy of carboplatin and weekly paclitaxel administered to a patient with NSCLC receiving hemodialysis for ESRD.

\section{Materials and methods}

The patient was a 68-year-old Japanese man who had been undergoing hemodialysis for 3 years to treat ESRD of unknown origin. In February 2010, he was admitted to 
Okazaki City Hospital due to loss of consciousness caused by severe aortic stenosis. A mass measuring $58 \mathrm{~mm}$ in the upper lobe of the right lung with a small amount of right pleural effusion was confirmed by computed tomography (Fig. 3a, b) so that he was referred to the Department of Respiratory Medicine. He was clinically diagnosed with adenocarcinoma of the lung (cT2bN1M1a, stage IV) by right thoracentesis (Fig. 4a, b). In accordance with the Eastern Cooperative Oncology Group (ECOG) performance status (PS) 1, chemotherapy was recommended [7]. Arteriovenous fistulas located in the left forearm were used for vascular access. The dialysate flow was $500 \mathrm{ml} / \mathrm{min}$ with a blood flow of $200 \mathrm{ml} / \mathrm{min}$. Hemodialysis was provided for 4-h, three times per week. The dialysate (D Dry 3.0S, NIKKISO Co., Ltd., Ishikawa, Japan) contained $2 \mathrm{mEq} / \mathrm{l}$ of potassium and $3 \mathrm{mEq} / \mathrm{l}$ of calcium. The bicarbonate content of the dialysate was $25 \mathrm{mEq} / \mathrm{l}$ and the acetic acid content was $10 \mathrm{mEq} / \mathrm{l}$. The membrane of the dialyzer was polysulfone with a surface area of $2.1 \mathrm{~m}^{2}$ (VPS-21HA, Asahi Kasei Kurare Medical Co., Ltd., Tokyo, Japan).

The patient's vital signs were normal and upon physical examination, body height was $157.7 \mathrm{~cm}$, body weight was $52.2 \mathrm{~kg}$, consciousness level was alert, a cardiac systolic murmur was present, breath sounds were clear, and neurological findings were normal. The laboratory data were as follows: WBC count $8,400 / \mathrm{mm}^{3}$, hemoglobin level $(\mathrm{Hb}) 13.5 \mathrm{~g} / \mathrm{dl}$, platelet count $147,000 / \mathrm{mm}^{3}$, blood urea nitrogen level (BUN) $55 \mathrm{mg} / \mathrm{dl}$, creatinine level $10.54 \mathrm{mg} / \mathrm{dl}$, and a serum CEA level of $15.6 \mathrm{mg} / \mathrm{dl}$. The pleural effusion CEA level was $364 \mathrm{mg} / \mathrm{dl}$. Both EGFR and KRAS genotypes in the tumor cells were wild type. Echocardiographic findings were as follows: an ejection fraction of $44 \%$, mean pressure gradient $53 \mathrm{mmHg}$, and maximum aortic velocity of $4.78 \mathrm{~m} / \mathrm{s}$. The patient was scheduled to receive combination chemotherapy of carboplatin and weekly paclitaxel. A carboplatin dose of $120 \mathrm{mg}$ was calculated with the Calvert formula as follows: the glomerular filtration rate (GFR) was assumed to be $0 \mathrm{ml} / \mathrm{min}$, the target area under blood concentration versus time curve (AUC) was $5 \mathrm{mg} / \mathrm{ml} \mathrm{min}$; thus the carboplatin dose using the Calvert formula was determined at $[5 \times(0+25)=125 \mathrm{mg}]$, and the single digit was then omitted [8]. On the first day, carboplatin was administered as a 1-h intravenous infusion followed by a 1-h infusion of paclitaxel at a dose of $100 \mathrm{mg}\left(70 \mathrm{mg} / \mathrm{m}^{2}\right)$, and hemodialysis was performed for 4-h starting 1 -h after administration of carboplatin. On the 8th and 15th days, hemodialysis was performed starting 1-h after administration of paclitaxel.

\section{Results}

Combination chemotherapy was initiated in March 2010. Pleurodesis was not attempted due to the small amount of pleural effusion. On the 15th day of the first cycle, paclitaxel administration was skipped due to grade 3 neutropenia. Fever was not observed. Neutropenia was expected to worsen so that a granulocyte-colony stimulating factor (G-CSF) was administered for 3 days. At the second cycle, the dose of carboplatin was unchanged to avoid insufficient amounts of dosing. The paclitaxel dose was reduced to $60 \mathrm{mg} / \mathrm{m}^{2}$, but its administration on the 15 th day was skipped due to grade 3 neutropenia and G-CSF was administered for 4 days. At the 

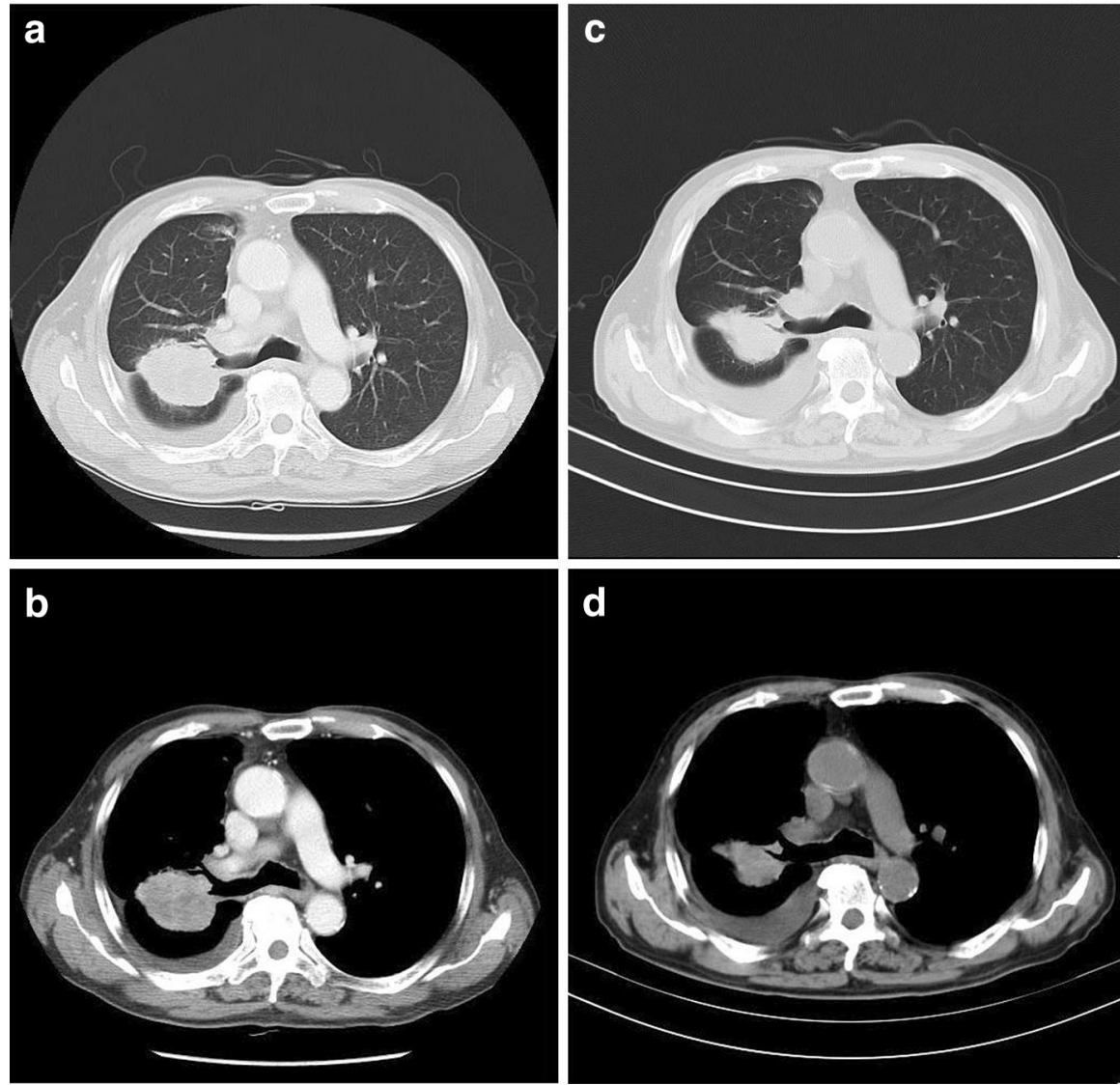

Fig. 3 Chest computed tomography taken both at the beginning $(\mathbf{a}, \mathbf{b})$ and at the third cycle (c, d) of chemotherapy show a mass on the upper lobe of the right lung with pleural effusion. Tumor response was evaluated as stable disease according to RECIST guidelines (version 1.1)

third cycle, the paclitaxel dose was reduced to $50 \mathrm{mg} / \mathrm{m}^{2}$, but administration on the 15 th day was postponed by 1 day due to loss of consciousness. Thoracentesis was re-performed on the 28th day due to the progression of right pleural effusion. The CEA level of the pleural effusion dramatically fell to $30.7 \mathrm{mg} / \mathrm{dl}$ and some target lesions were assessed as stable disease (Fig. 3c, d). It was, therefore, decided that the fourth cycle would be continued. On the 15th day of the fourth cycle, administration was skipped due to grade 3 dyspnea caused by exacerbation of heart failure so that chemotherapy was terminated. Grade 3 anemia developed on the 18th day but was corrected without requiring red blood cell transfusion. Dyspnea, cardiomegaly, and congestion of the lungs gradually improved after the end of chemotherapy and the patient visited our outpatient clinic every few weeks. Peripheral neuropathy was not observed. However, he contracted severe pneumonia and died in October 2010, 9 months after the diagnosis of lung cancer. 


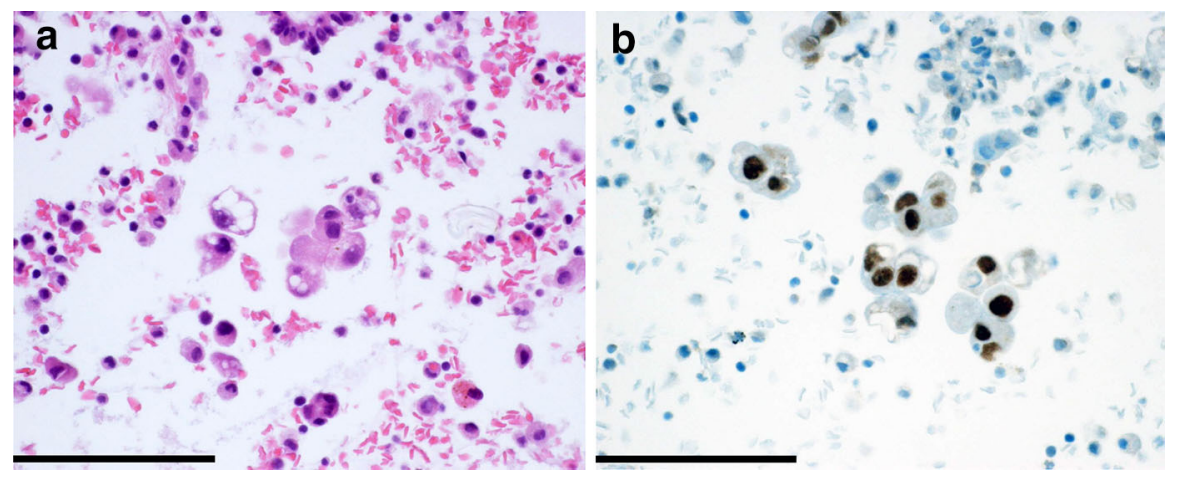

Fig. 4 Cytological examination of pleural effusion was positive for malignancy. Atypical cells had insufficient mucus in cytoplasm and unevenly distributed nuclei (Papanicolaou staining, a: $\times 1,000$; bar $=50 \mu \mathrm{m})$. Immunocytochemical staining for TTF-1 positive $(\mathbf{b}: \times 400 ;$ bar $=100 \mu \mathrm{m})$. Atypical cells were diagnosed as adenocarcinoma of lung in consideration of immunocytochemical staining for p53 overexpression positive, calretinin negative, and CK5/6 negative (data not shown)

\section{Discussion}

The number of patients with ESRD has been increasing globally and the risk of cancer in patients with ESRD is higher than that in the general population [9-12]. Carboplatin, cis-Diammine-1,1-cyclobutane dicarboxylate platinum(II), has a cyclobutane dicarboxylate ligand as a substitute for the chloride ligands of cisplatin. Due to the chelate effect of the cyclobutane dicarboxylate ligand, carboplatin remains intact and stable for a longer time in body fluids, while it is converted to reactive platinum complex by substituting the cyclobutane dicarboxylate ligand for aqua and hydroxyl ligands in the cells. The hydroxyl site of platinum bind to DNA, forming a variety of intrastrand and interstrand adducts, the most abundant of which are 1,2-intrastrand cross-links between the N7 atoms of the two adjacent guanine bases [13]. The 1,2-intrastrand cross-links locally unwind and bend the double-stranded DNA toward the major groove, while the disturbance of the DNA secondary structure seems to be the ultimate reason for the inhibition of DNA replication and/or transcription, and for triggering apoptosis [14]. Carboplatin is less nephrotoxic than cisplatin. Despite the fact that higher total platinum levels are present in the nephron following carboplatin administration, only a small fraction is in the form of the reactive platinum species. Carboplatin doses can be regulated according to renal function so that it is favorable for patients with impaired renal function, including those who receive hemodialysis [4, 15]. The Calvert formula, dose $(\mathrm{mg})=\mathrm{AUC}(\mathrm{mg} / \mathrm{ml} \mathrm{min}) \times[\mathrm{GFR}(\mathrm{ml} / \mathrm{min})+25]$, is clinically well accepted to calculate the dose of carboplatin according to renal function. However, since the Calvert formula was developed on the basis of data from patients with GFRs ranging from 33 to $135 \mathrm{ml} / \mathrm{min}$, its validity in patients with renal insufficiency who are undergoing hemodialysis remains to be confirmed [8]. It is generally thought that protein-bound drugs are difficult to eliminate in hemodialysis. It has been reported that the protein binding rate of carboplatin is 
low during the initial distribution phase and rises to approximately $40 \%$ or more after $24-h$ in the elimination phase $[16,17]$. Therefore, various options on the timing of hemodialysis in patients receiving carboplatin have been conceived. In a case in which $125 \mathrm{mg}$ of carboplatin was administered to produce a target AUC of $5.0 \mathrm{mg} / \mathrm{ml} \mathrm{min}$, the actual AUCs were reported at $2.21,4.43$, and $6.1 \mathrm{mg} / \mathrm{ml} \mathrm{min}$ when hemodialysis was started after 1.5-, 16-, and 24-h administration of carboplatin, respectively $[18,19]$. Grade 3 neutropenia was observed when conditions for the start of hemodialysis were modified at $16-\mathrm{h}$ (but not at 1.5-h) after carboplatin administration [19]. For the current case, hemodialysis was started 1-h after carboplatin administration in the distribution phase due to safety concerns.

Paclitaxel is isolated from the bark of Pacific yew trees and its antitumor activity is well confirmed. Paclitaxel has the capacity to bind tubulin and stabilize microtubules, thus modifying the cytoskeleton architecture and blocking the cell cycle in the G2/M phase $[20,21]$. The fundamental role of paclitaxel is to promote tubulin assembly, however, the normal function of a cell requires that the microtubules should be in dynamic equilibrium with the monomeric tubulins, and any compound that disrupts this equilibrium is likely to be a cytotoxic agent. Paclitaxel acts as an anticancer agent primarily through its interaction with tubulin, and an understanding of its conformation in the binding pocket of tubulin will be important in elucidating its mechanisms [22]. It is mainly metabolized to 6-hydroxypaclitaxel and 3'-phenyl-hydroxypaclitaxel by liver microsomal CYP2C8 and CYP3A4, respectively, and then eliminated through the biliary route [23].

For the present case, a combination of carboplatin and weekly paclitaxel was selected instead of some single-agent regimens for the following reasons: the combination of carboplatin and paclitaxel is currently one of the standard regimens for first line chemotherapy in patients with NSCLC and ovarian cancer, and the use of this regimen in cancer patients receiving hemodialysis for ESRD has previously been reported [18, 24-26]. Not only chronologic age but comorbidity has also been reported to be associated with more severe toxicity and lower chemotherapy dose intensity for NSCLC patients [27]. In elderly NSCLC patients, the combination of carboplatin and weekly paclitaxel was associated with survival benefits as compared with single-agent chemotherapy [28]. Some weekly combination regimens were preferable for elderly patients or those with severe comorbidity [29-31]. Pemetrexed was not selected since its safety for ESRD patients receiving hemodialysis has yet to be confirmed, while gefitinib was not selected due to the EGFR genotype of the lung cancer.

The dose-limiting toxicity of both carboplatin and paclitaxel was thought to be myelosuppression. Grade 3 neutropenia, which is mainly assumed to be due to paclitaxel toxicity, was observed during the first to third cycles in the current case. The carboplatin dose was not changed since the actual AUC was assumed to be lower than the target AUC according to past reports, whereas the paclitaxel dose was reduced to $60 \mathrm{mg} / \mathrm{m}^{2}$ weekly for the second cycle and $50 \mathrm{mg} / \mathrm{m}^{2}$ weekly for the third and fourth cycles. Grade 3 anemia ( $\mathrm{Hb} 7.9 \mathrm{~g} / \mathrm{dl}$ ) developed at the fourth cycle, but was corrected without requiring red blood cell transfusion. At the fourth cycle, grade 3 dyspnea due to exacerbation of heart failure emerged and dyspnea recovery was evident after the termination of chemotherapy. 
In summary, for the present case, a combination of carboplatin and weekly paclitaxel was administered to a patient with NSCLC undergoing hemodialysis for ESRD and severe aortic stenosis. Under conditions in which hemodialysis was started 1-h after administration of carboplatin, adverse events were tolerable and chemotherapy was administered safely for four courses. This work outlines a case strategy as reference for the effective treatment and management of future cases. It was found that the combination of carboplatin and weekly paclitaxel can be considered a promising regimen for NSCLC patients receiving hemodialysis.

Acknowledgments The author expresses sincere thanks to Dr. Tomoya Shimokata and Dr. Takayuki Ando for their valuable discussions on this work.

Conflict of interest The author has no conflict of interest.

Open Access This article is distributed under the terms of the Creative Commons Attribution License which permits any use, distribution, and reproduction in any medium, provided the original author(s) and the source are credited.

\section{References}

1. NSCLC Meta-Analysis Collaborative Group, J. Clin. Oncol. 26, 4617 (2008)

2. K. Hotta, K. Matsuo, H. Ueoka, K. Kiura, M. Tabata, M. Tanimoto, J. Clin. Oncol. 22, 3852 (2004)

3. J.H. Schiller, D. Harrington, C.P. Belani, C. Langer, A. Sandler, J. Krook, J. Zhu, D.H. Johnson, N. Engl, J. Med. 346, 92 (2002)

4. M.J. Egorin, D.A. Van Echo, S.J. Tipping, E.A. Olman, M.Y. Whitacre, B.W. Thompson, J. Aisner, Cancer Res. 44, 5432 (1984)

5. M.H. Woo, D. Gregornik, P.D. Shearer, W.H. Meyer, M.V. Relling, Cancer Chemother. Pharmacol. 43, 92 (1999)

6. M. Tomita, H. Kurata, Y. Aoki, K. Tanaka, J.J. Kazama, Anticancer Drugs 12, 485 (2001)

7. M.M. Oken, R.H. Creech, D.C. Tormey, J. Horton, T.E. Davis, E.T. McFadden, P.P. Carbone, Am. J. Clin. Oncol. 5, 649 (1982)

8. A.H. Calvert, D.R. Newell, L.A. Gumbrell, S. O’Reilly, M. Burnell, F.E. Boxall, Z.H. Siddik, I.R. Judson, M.E. Gore, E. Wiltshaw, J. Clin. Oncol. 7, 1748 (1989)

9. S. Pastan, J. Bailey, N. Engl, J. Med. 338, 1428 (1998)

10. R.K. Verbeeck, F.T. Musuamba, Eur. J. Clin. Pharmacol. 65, 757 (2009)

11. H. Niikura, T. Koizumi, K. Ito, K. Okamura, N. Yaegashi, Anticancer Drugs 14, 735 (2003)

12. P. Maisonneuve, L. Agodoga, R. Gellert, J.H. Stewart, G. Buccianti, A.B. Lowenfels, R.A. Wolfe, E. Jones, A.P. Disney, D. Briggs, M. McCredie, P. Boyle, Lancet 354, 93 (1999)

13. A.P. Silverman, W. Bu, S.M. Cohen, S.J. Lippard, J. Biol. Chem. 277, 49743 (2002)

14. M. Benedetti, J. Malina, J. Kasparkova, V. Brabec, G. Natile, Environ. Health Perspect. 110, 779 (2002)

15. R.S. Go, A.A. Adjei, J. Clin. Oncol. 17, 409 (1999)

16. M. Hiraike, Y. Hiraki, N. Misumi, K. Hanada, Y. Tsuji, H. Kamimura, Y. Karube, K. Kashiwabara, Cancer Chemother. Pharmacol. 69, 845 (2012)

17. M. Sooriyaarachchi, A. Narendran, J. Gailer, Metallomics 3, 49 (2011)

18. T. Oguri, T. Shimokata, M. Inada, I. Ito, Y. Ando, Y. Sasaki, Y. Haswgawa, Cancer Chemother. Pharmacol. 66, 813 (2010)

19. M. Watanabe, Y. Aoki, M. Tomita, T. Sato, Y. Takaki, N. Kato, M. Kikuchi, H. Kase, K. Tanaka, Gynecol. Oncol. 84, 335 (2002)

20. P.B. Schiff, J. Fant, S.B. Horwitz, Nature 277, 665 (1979)

21. M.C. Wani, H.L. Taylor, M.E. Wall, P. Coggon, A.T. McPhail, J. Am. Chem. Soc. 93, 2325 (1971)

22. D.G. Kingston, Phytochemistry 68, 1844 (2007) 
23. T. Cresteil, B. Monsarrat, P. Alvinerie, J.M. Treluyer, I. Vieira, M. Wright, Cancer Res. 54, 386 (1994)

24. Y. Abe, K. Tanaka, K. Matsumoto, K. Takayama, H. Inoue, M. Izumi, H. Inoue, Y. Nakanishi, Nihon Kokyuki Gakkai Zasshi 48, 769 (2010)

25. H. Hashimoto, Y. Oshika, K. Obara, Y. Tanaka, E. Shimizu, Gan To Kagaku Ryoho 37, 1553 (2010)

26. N. Jeyabalan, H.W. Hirte, F. Moens, Int. J. Gynecol. Cancer 10, 463 (2000)

27. T.R. Asmis, K. Ding, L. Seymour, F.A. Shepherd, N.B. Leighl, T.L. Winton, M. Whitehead, J.N. Spaans, B.C. Graham, G.D. Goss, J. Clin. Oncol. 26, 54 (2008)

28. E. Quiox, G. Zalcman, J.P. Oster, V. Westeel, E. Pichon, A. Lavole, J. Dauba, D. Debieuvre, P.J. Souquet, L. Bigay-Game, E. Dansin, M. Poudenx, O. Molinier, F. Vaylet, D. Moro-Sibilot, D. Herman, J. Bennouna, J. Tredaniel, A. Ducolone, M.P. Lebitasy, L. Baudrin, S. Laporte, B. Milleron, Lancet 378, 1079 (2011)

29. C.P. Belani, S. Ramalingam, M.C. Perry, R.V. LaRocca, D. Rinaldi, P.S. Gable, W.J. Tester, J. Clin. Oncol. 26, 468 (2008)

30. T. Sakakibara, A. Inoue, S. Sugawara, M. Maemondo, T. Ishida, K. Usui, T. Abe, M. Kanbe, H. Watanabe, Y. Saijo, T. Nukiwa, Ann. Oncol. 21, 795 (2010)

31. T. Hirose, Y. Nakagawa, Jpn. J. Lung Cancer 48, 285 (2008) 